\title{
A calm view of video violence
}

Studies of violence in the media and its effects on people are clouded by overheated rhetoric and exaggerated claims. More clarity is needed, both in the science and in the way it is discussed.

$\mathrm{T}$ here are good reasons to be troubled by the violence that pervades the media. Movies, television and video games are full of gunplay and bloodshed, and one might reasonably ask what's wrong with a society that presents videos of domestic violence as entertainment. Of course, the same questions could have been raised about watching Macbeth, or Punch and Judy. Let's face it, people have always enjoyed watching other people's mayhem.

Most researchers agree that the causes of real-world violence are complex. A 1993 study by the US National Academy of Sciences listed "biological, individual, family, peer, school, and community factors" as all playing their parts. And a 2001 report by the US surgeon general concluded that "the preponderance of evidence indicates that violent behavior seldom results from a single cause; rather, multiple factors converging over time contribute to such behavior".

Viewing abnormally large amounts of violent television and video games may well contribute to violent behaviour in certain individuals. The trouble comes when researchers downplay uncertainties in their studies or overstate the case for causality. Sceptics were dismayed several years ago when a group of societies including the American Medical Association, the American Psychological Association and the American Academy of Pediatrics tried to end the debate by issuing a joint statement: "At this time, well over 1000 studies ... point overwhelmingly to a causal connection between media violence and aggressive behavior in some children."

Freedom-of-speech advocates accused the societies of pandering to politicians, and even disputed the number of studies (most were review articles and essays, they said). When Jonathan Freedman, a social psychologist at the University of Toronto in Canada, reviewed the literature, he found only 200 or so studies of television-watching and aggression. And when he weeded out "the most doubtful measures of aggression", only $28 \%$ supported a connection.

The critical point here is causality. The alarmists say they have proved that violent media cause aggression. But the assumptions behind their observations need to be examined. When labelling games as violent or non-violent, should Pac-Man gobbling a ghost really be counted as a violent event? And when experimenters measure physiological arousal, or record the time it takes game players to read 'aggressive' or 'non-aggressive' words from a list, can we be sure what they are actually measuring? The intent of the new Harvard Center on Media and Child Health, to collect and standardize studies of media violence in order to compare their methodologies, assumptions and conclusions, is an important step in the right direction.

Another appropriate step would be to tone down the crusading rhetoric until we know more. Several researchers write, speak and testify prolifically on the threat posed by violence in the media. That is, of course, their privilege. But when doing so, they often come out with statements that the matter has now been settled, drawing criticism from colleagues. In response, the alarmists accuse critics and news reporters of being duped by the entertainment industry. Such clashes help neither science nor society.

\section{The grand challenges facing physics}

\section{It would be easy to delay the prioritization of major new projects at US physics laboratories, but it needs to be done.}

$t$ is more than a decade since the US Department of Energy (DOE)

last set out a programme of major new facilities for its network of

laboratories. The intention of Ray Orbach, head of the DOE Office of Science, to draw up such a list should be welcomed by researchers.

The DOE is understandably tight-lipped about its plan (see page 357). It has little enough money to support current operations, and there is a very real risk that publishing the list will trigger conflict between the winners and losers. But a list of priorities will soon be needed. With most individual investigators based at universities, the main function of the department's laboratory network is to build and house facilities that the universities themselves could not afford. Such projects take upwards of a decade to plan and construct.

The choices to be made leave many researchers understandably nervous. In the context of frozen budgets - a context that the Office of Science has largely endured since the cancellation of the Superconducting Super Collider in 1993 - facilities must be built at the short-term expense of the very people who will use them.

But with no major facility planned since the Spallation Neutron Source, now under construction at the Oak Ridge National Laboratory in Tennessee, a backlog of potential opportunities is accruing. Orbach is right to bite the bullet and prepare a new plan. It is understandable that he wants to be cautious in discussing its contents, in advance of their approval by his boss, energy secretary Spencer Abraham, and by the bean-counters at the White House Office of Management and Budget.

In their different ways, Europe and Japan are also finding it difficult to build large facilities, faced with problems in garnering the necessary support. The fusion project ITER and a linear particle collider (as well as upgrades at CERN's Large Hadron Collider) will be global projects, but there is no consistent framework for these to be considered by the nations that might want to build them. The Organisation for Economic Cooperation and Development's Global Science Forum remains the most credible body for such discussions, but its influence will need to grow if it is to fulfil this role.

In the meantime, Orbach can draw some encouragement from Congress's recent support for his office (see page 361 ). Progress seems to have been made in convincing law-makers that the DOE's physics programmes, in particular, are a valuable part of the nation's scientific portfolio. Extra impetus should also come from the gradual expansion of the National Institutes of Health's role in equipping large facilities, such as synchrotron light sources, that are also used by biologists. After a difficult spell, this process is the best opportunity that the DOE has had for years to plan properly for its laboratories' futures. 